\title{
ANALYSIS OF TUBERCULOSIS TREATMENT SUITABILITY AND THE DRUG SUPERVISOR'S ROLE IN A COMMUNITY HEALTH CENTER IN PADEMANGAN SUBDISTRICT, NORTH JAKARTA
}

\author{
CITRA FEBRIONY ${ }^{1}$, PURWANTYASTUTI ${ }^{1}$, MEANALDI RASMIN ${ }^{2}$, VIVIAN SOETIKNO ${ }^{1 *}$
}

${ }^{1}$ Department of Pharmacology and Therapeutics, Faculty of Medicine, Universitas Indonesia, Jakarta, Indonesia. ${ }^{2}$ Department of Pulmonology and Respiratory Medicine, Faculty of Medicine, Universitas Indonesia, Jakarta, Indonesia. Email: Vivian_09st@yahoo.com

Received: 30 September 2018 Revised and Accepted: 14 March 2019

\section{ABSTRACT}

Objective: Appropriate tuberculosis (TB) treatment guidelines are one of the many factors that influence the success of TB treatment. The patient's drug supervisor is a functional role that is part of the directly observed treatment short course, a program to support the success of TB treatment. The aim of this study was to analyze the TB treatment suitability in a community health center and the benefit of treatment compliance supervision by the patient's designated drug supervisor.

Methods: We conducted a cross-sectional study in the Community Health Center of Pademangan subdistrict, North Jakarta, involving 205 subjects to analyze appropriate fixed-dose combination (FDC) anti-TB drug administration and an experimental study involving 23 control group TB patients and 23 intervention group TB patients to assess the benefit of supervision by each patient's drug supervisor.

Results: The association of FDC anti-TB drug side effects with the success of TB treatment was not statistically significant (p=0.173). There was an increase in drug supervisor knowledge of $8.6 \%$ in the intervention group and $13 \%$ in the control group. There was no statistically significant association between the knowledge of the drug supervisor and the $2^{\text {nd }}$ month $(p=0.575)$ and the $6^{\text {th }}$ month of sputum treatment

Conclusion: Minor side effects of FDC anti-TB drug did not affect the success of TB treatment; therefore, treatment was continued if these adverse events occurred. There were no correlations between the drug supervisor knowledge level with medication compliance or with sputum conversion (months 2 and 6).

Keywords: Fixed-dose combination, Drug supervisor, Tuberculosis.

(C) 2019 The Authors. Published by Innovare Academic Sciences Pvt Ltd. This is an open access article under the CC BY license (http://creativecommons. org/licenses/by/4. 0/) DOI: http://dx.doi.org/10.22159/ijap.2019.v11s1.030

\section{INTRODUCTION}

Tuberculosis (TB) is a contagious infectious disease that receives great attention worldwide because it has the highest mortality rate in the world [1,2]. The disease is caused by bacterial infection of Mycobacterium TB that is transmitted through the air. In 2014, 9 million people were infected with TB each year worldwide, 1.5 million people died of TB, and $>3$ million people with TB were undiagnosed or treated. On average, every person with undiagnosed TB infects 15 people each year.

An appropriate TB treatment guide is one of the factors that influence the success of TB treatment. Several factors should be taken into consideration, such as the characteristics of the bacteria or acidresistant bacilli (BTA) itself, the clinical characteristics of patients with heterogeneity, patient behavior or attitudes, quality of health care, presence or absence of TB coinfection-human immunodeficiency virus (TB-HIV), anti-TB drug (anti-TB drug) side effects, delayed administration of anti-TB drug, and multidrug-resistant TB (MDR-TB) [3]. These factors can be assessed and traced to evaluate the success of TB treatment because direct supervision is required to determine the attitudes and behaviors of real patients.

According to the World Health Organization, a drug use study (DUS) is one that covers the marketing, distribution, and prescribing and use of medicines in the community by considering the patient's clinical and socioeconomic consequences. Pharmacovigilance involves the monitoring, evaluation, and prevention of adverse effects, especially long-term and short-term side effects, associated with the administration of medicines. DUS and pharmacovigilance are parts of pharmacoepidemiology [4].
Treatment of TB patients using fixed-dose combination (FDC) drugs has not been able to eradicate $100 \%$ of TB in patients in Indonesia, which still has the second highest prevalence of TB patients in the world. The number of cases of the pulmonary TB in DKI Jakarta Province in 2012 was 24,500 [5]. It is estimated that every year, 253 new TB cases are found, of which about one-third of patients are located around the Community Health Center, Pademangan subdistrict, North Jakarta [6].

The aim of the present study was to assess the suitability of FDC TB treatment and the role of the drug supervisor (a designated person who helps ensure a patient's treatment compliance) in a Community Health Center in North Jakarta, Indonesia. Please note that the drug supervisor is a part of the directly observed treatment short course, which is a program designed to support the successful treatment of TB patients.

\section{METHODS}

We conducted a cross-sectional study to determine the suitability of TB treatment at a Community Health Center by reviewing medical records' data and TB-01 card from 2012 to 2014. In addition, we conducted an experimental study in which we provided counseling and training to one group of drug supervisors and none to another group as the control. The drug supervisors were randomly assigned to the intervention and control groups. Drug supervisors are often family members who may live with the TB patient.

For research purposes 1-4, the study was conducted at the Community Health Center of Pademangan subdistrict, North Jakarta. For research purposes 5-8, the study was conducted at the Community Health Center of Pademangan subdistrict, North Jakarta, and at the Community Health Center of East Pademangan, North Jakarta. The study was conducted from 
January 2015 to December 2015. For research purposes 1-4, the study group comprised all the TB patients, and for research purposes $5-8$, the study group comprised TB patients supervised by drug supervisors.

The study sample was taken from a population that met the following inclusion criteria and did not meet the exclusion criteria. For the research purposes 1-4, the inclusion criteria were pulmonary and extrapulmonary TB patients, age $\geq 17$ years, and the exclusion criteria were patients with MDR-TB, TB-HIV, or were pregnant and had incomplete or unreadable medical records' data. For research purposes 5-8, the inclusion criteria were drug supervisor patients with new pulmonary $\mathrm{TB}$ or treatment of $<1$ month with positive smears or negative smears, but a positive radiological examination, drug supervisor patients with pulmonary TB, age 17-65 years old, and were willing to sign informed consent, and the exclusion criteria were drug supervisor pulmonary TB patients in Category II anti-TB drug, drug supervisor MDR-TB patients, and drug supervisor pregnant TB patients.

For research purposes 1-4, all the data (medical records and TB-01 cards TB patients starting from 2012 to 2014) were sampled. For the research purposes 5-8, consecutive sampling was used. The subjects were randomly selected for placement in intervention or control groups. For research purposes 1-4, the approximate sample size was calculated using a single large sample formula to estimate the proportion of a population according to the following equation:

$$
\mathrm{n}=\mathrm{Z} \alpha 2 \mathrm{PQ} / \mathrm{d} 2 \text { with } \mathrm{Z} \alpha=95 \%
$$

For research purposes 5-8, the approximate sample size was calculated using a single large sample formula to estimate the proportion of a population according to the following equation:

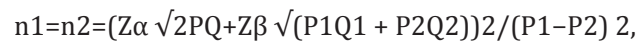

With $\mathrm{Z} \alpha=95 \%$ and a power hypothesis of $80 \%$

All the patient data were kept confidential in accordance with the research code of conduct. Approval of the research protocol was obtained from the (1) research ethics committee of the Faculty of Medicine, University of Indonesia, (2) subdepartment of the city health administration of North Jakarta, and (3) Head of Community Health Center Subdistrict of Pademangan North Jakarta.

Data collection was performed from medical records and TB-01 cards from 2012 to 2014. Data collection was also performed through questionnaires given and filled by the drug supervisor (direct interview) before and after training in both research groups. The first questionnaire (pretest) was given when the drug supervisor began treatment of the patient and after receiving counseling from TB officers in the Community Health Center. After the pre-test, the research subjects (drug supervisors) belonging to the intervention group received counseling from researchers on basic TB knowledge and drug supervisor duties; however, the control group did not. 1 week later, after pre-test replenishment, the researcher gave the second questionnaire (post-test) with the same question to both of the groups (control group and intervention group). Knowledge of the drug supervisor was considered sufficient for a score $\geq 8$ of 10 questions, with the score including questions 3,5 , and 6 .

\section{Statistical analysis}

All the research data were recorded in a manual and an electronic form. Descriptive and analytical statistical analyses were performed. The intention to treat method was used to analyze the data. The statistical system used was SPSS 22.0 software.

\section{RESULTS}

For research purposes 1-4, the data collection of this research was performed using the TB patient's medical records and TB-01 cards, with the data collected from the 205 subjects who fulfilled the inclusion criteria. The data were collected in the subdistrict of Pademangan, North Jakarta, from 2012 to 2014.

Descriptive analysis of the 205 study subjects' demographic characteristics was performed. The characteristics included sex, age, weight, type of TB, medication status, weight gain, and comorbidities (Table 1). The frequency distribution analysis of the data included the number of patients receiving FDC, accuracy of the FDC category, accuracy of the FDC indication, accuracy of the duration of FDC administration, accuracy of FDC dosage, presence/absence of side effects, frequency of smear examination before treatment, proportion of conversion BTA after 2 months and 6 months of treatment, and the presence or absence of a drug supervisor (Table 2).

Among the 205 subjects in this study, 197 (96.1\%) patients were in the FDC Category 1 and $8(3.9 \%)$ patients were in the FDC Category 2. $10(5.1 \%)$ patients received FDC Category 1 insertion and no $(0 \%)$ patients received Category 2 insertion.

$p=0.173$ was obtained (Fisher's test). $p>0.05$ result indicated that there was no significant relationship between the side effects and treatment success, with a prevalence ratio of 0.757 (95\% IK: 0.077-1.612).

For research purposes 5-8, a descriptive analysis of the demographic characteristics of the $46 \mathrm{~TB}$ patients in the experimental study was performed. The demographic characteristics included sex, age, educational level, occupation, and marital status (Table 3).

In the experimental study, $6(26.1 \%)$ of the 23 subjects had sufficient knowledge in the control group on the pre-test. $3(13.1 \%)$ of the 23 subjects had sufficient knowledge in the intervention group on the pre-test. $9(39.1 \%)$ of the 23 subjects had sufficient knowledge in the control group on the post-test. 5 (21.7\%) of the 23 subjects had sufficient knowledge in the intervention group on the post-test.

\begin{tabular}{|c|c|c|}
\hline No. & Variable & Frequency $n=205(\%)$ \\
\hline \multirow[t]{3}{*}{1.} & Sex & \\
\hline & Man & $128(62.4)$ \\
\hline & Woman & $77(37.6)$ \\
\hline \multirow[t]{3}{*}{2.} & Age (years) & \\
\hline & $17-54$ & $173(84.4)$ \\
\hline & $\geq 55$ & $32(15.6)$ \\
\hline \multirow[t]{5}{*}{3.} & Weight (kg) & \\
\hline & $30-37$ & $18(8.8)$ \\
\hline & $38-54$ & $136(66.3)$ \\
\hline & $55-70 \mathrm{~kg}$ & 4421.5 \\
\hline & $\geq 71 \mathrm{~kg}$ & $7(3.4)$ \\
\hline \multirow[t]{3}{*}{4.} & TB type & \\
\hline & Lung TB paru & $202(98.5)$ \\
\hline & Extra lung TB & $3(1.5)$ \\
\hline \multirow[t]{7}{*}{5.} & TB medication status & \\
\hline & Extra lung & $85(41.5)$ \\
\hline & Healed & $92(44.9)$ \\
\hline & Complete & $13(6.3)$ \\
\hline & Negligent & $3(1.4)$ \\
\hline & Dead & $12(5.9)$ \\
\hline & Moved & \\
\hline \multirow[t]{9}{*}{6.} & Weight increase & \\
\hline & *After 2 months of medication & \\
\hline & Increased & $102(49.8)$ \\
\hline & Constant & $36(17.6)$ \\
\hline & Decreased & $67(32.7)$ \\
\hline & *After 6 months of medication & \\
\hline & Increased & $125(70.6)$ \\
\hline & Constant & $27(15.3)$ \\
\hline & Decreased & $25(14.1)$ \\
\hline \multirow[t]{3}{*}{7.} & Comorbid & \\
\hline & Yes & $11(5.4)$ \\
\hline & No & $194(94.6)$ \\
\hline
\end{tabular}

Table 1: Demographic characteristics 
Table 2: Frequency distribution of the data based on research variables

\begin{tabular}{|c|c|c|}
\hline No. & Variable & Frequency n (\%) \\
\hline \multirow[t]{5}{*}{1.} & Number of patients receiving FDC & \\
\hline & Cat 1 & $199(97.1)$ \\
\hline & Cat 2 & $6(2.9)$ \\
\hline & Inflix cat 1 & $10(5.1)$ \\
\hline & Infilix cat 2 & $0(0)$ \\
\hline \multirow[t]{3}{*}{2.} & Accuracy of category FDC granting & \\
\hline & Accurate & $205(100)$ \\
\hline & Not accurate & $0(0)$ \\
\hline \multirow[t]{3}{*}{3.} & Accuracy of indication of FDC granting & \\
\hline & Accurate & $198(96.6)$ \\
\hline & Not accurate & $7(3.4)$ \\
\hline \multirow[t]{2}{*}{4.} & Accuracy of the duration of FDC & \\
\hline & Accurate & $141(74.2)$ \\
\hline \multirow[t]{3}{*}{5.} & Accuracy of FDC dosing side effects apparent & \\
\hline & Not accurate & $49(25.8)$ \\
\hline & Accurate & $176(85.9)$ \\
\hline \multirow[t]{2}{*}{6.} & BTA examination before medication & \\
\hline & Not accurate & $29(14.1)$ \\
\hline \multirow[t]{4}{*}{7.} & BTA sputum conversion & \\
\hline & *After 2 months of medication & \\
\hline & Yes & $13(6.3)$ \\
\hline & No & $192(93.7)$ \\
\hline \multirow[t]{3}{*}{8.} & *After 6 months of medication & \\
\hline & $(+)$ & $111(54.1)$ \\
\hline & $(-)$ & $94(45.9)$ \\
\hline \multirow[t]{7}{*}{9.} & Drug supervisor & \\
\hline & Yes & $79(71.2)$ \\
\hline & No & $32(28.8)$ \\
\hline & Yes & $90(81.1)$ \\
\hline & No & $21(18.9)$ \\
\hline & Yes & $162(79.0)$ \\
\hline & No & $43(21.0)$ \\
\hline
\end{tabular}

In the intervention group, there was an increase in the percentage of drug supervisors with sufficient knowledge, from $13.1 \%$ to $21.7 \%$ (increase of 8.6\%); however, the control group also increased from $26.1 \%$ to $39.1 \%$ (increase of $13 \%$ ).

Compliance with treatment for 6 months was $100 \%$ among the patients supervised by the 46 research subjects (drug supervisors). There was no correlation between drug supervisor knowledge and patient compliance with TB treatment for 6 months (the null hypothesis was correct). The number of drug supervisors with adequate knowledge of medication was 14 (30.4\%), and 32 (69.6\%) did not.

There was no significant correlation between knowledge of the drug supervisor and sputum TB patients after 2 months of treatment $(p=0.575$, Fisher's exact test; odds ratio 1061 [95\% IK: 0.978-1.151]).

There was $100 \%$ successful sputum conversion after 6 months among the 46 research subjects. There was no significant correlation between the knowledge of the drug supervisor and sputum conversion after 6 months of treatment (null hypothesis was true). However, the number of drug supervisors with sufficient knowledge of successful conversion was 14 (30.4\%) and 32 (69.6\%) for those without sufficient knowledge.

There was $100 \%$ compliance with TB treatment among the 46 research subjects. There was no correlation between TB treatment for 6 months and sputum conversion after 2 months of treatment. The number of patients who adhered to successful treatment of sputum after 2 months was 44 (95.6\%), and 2 (4.4\%) did not.

There was no significant correlation between TB treatments for 6 months of sputum conversion. The number of patients who adhered to successful treatment sputum after 6 months of treatment was $46(100 \%)$, and there were no $(0 \%)$ unsuccessful conversions.
Table 3: Demographic characteristics data

\begin{tabular}{|c|c|c|}
\hline Variable & $\begin{array}{l}\text { Control group } \\
n=23(\%)\end{array}$ & $\begin{array}{l}\text { Intervention } \\
\text { group } n=23(\%)\end{array}$ \\
\hline \multicolumn{3}{|l|}{ Gender } \\
\hline Man & $5(21.7)$ & $7(30.4)$ \\
\hline Woman & $18(78.3)$ & $16(69.6)$ \\
\hline \multicolumn{3}{|l|}{ Age (years) } \\
\hline$<30$ & $5(21.7)$ & $5(21.7)$ \\
\hline $30-49$ & $12(52.2)$ & $11(47.9)$ \\
\hline$>49$ & $6(26.1)$ & $7(30.4)$ \\
\hline \multicolumn{3}{|l|}{ Education status } \\
\hline Elementary & $5(21.7)$ & $14(60.9)$ \\
\hline Junior high & $5(21.7)$ & $4(17.4)$ \\
\hline Senior high & $10(43.5)$ & $4(17.4)$ \\
\hline High & $3(13.1)$ & $1(4.3)$ \\
\hline \multicolumn{3}{|l|}{ Job } \\
\hline Employed & $13(56.5)$ & $9(39.1)$ \\
\hline Unemployed & $10(43.5)$ & $14(60.9)$ \\
\hline \multicolumn{3}{|l|}{ Marital status } \\
\hline Married & $19(82.6)$ & $19(82.6)$ \\
\hline Single & $4(17.4)$ & $4(17.4)$ \\
\hline \multicolumn{3}{|c|}{ BTA sputum conversion } \\
\hline \multicolumn{3}{|c|}{ *After 2 months of medication } \\
\hline Conversion (+) & $22(95.6)$ & $22(95.6)$ \\
\hline Conversion (-) & $1(4.4)$ & $1(4.4)$ \\
\hline \multicolumn{3}{|c|}{ *After 6 months of medication } \\
\hline Conversion (+) & $23(100)$ & $23(100)$ \\
\hline Conversion (-) & $0(0)$ & $0(0)$ \\
\hline \multicolumn{3}{|c|}{$\begin{array}{l}\text { Relationship between drug } \\
\text { supervisor and patient }\end{array}$} \\
\hline Husband/wife & $5(21.7)$ & $8(34.8)$ \\
\hline Children & $4(17.4)$ & $3(13.1)$ \\
\hline Parents & $1(4.3)$ & $10(43.5)$ \\
\hline Siblings & $8(34.8)$ & $1(4.3)$ \\
\hline Others & 5 (21.7) & $1(4.3)$ \\
\hline
\end{tabular}

\section{DISCUSSION}

In the assessment of the suitability of FDC administration, 198 (96.6\%) TB patients were in accordance with the indication of FDC administration, whereas 7 (3.4\%) were not. The proper indications for FDC administration were patients who had been diagnosed as having TB (clinical symptoms and investigation) and were suitable for FDC anti-TB drug treatment, and improper indications were patients who tested sputum smear negative $(-)$, had no lung radiology examination, but had already been given FDC anti-TB drugs. This is not appropriate because TB drug delivery should be given to patients who have been diagnosed as having TB through clinical symptoms and investigations that have been established.

Based on the accuracy of the duration of FDC, it was found that $141(74.2 \%)$ subjects were correctly indicated; however, $49(25.8 \%)$ were inappropriate subjects. The duration of FDC depended on the type of TB suffered, namely pulmonary TB (6 months) or extra lung (depending on the type of TB). The duration of FDC administration also depended on comorbidities of the TB patients (e.g., TB patients with Type 2 diabetes mellitus were treated for 9 months). The inaccuracy of the duration of FDC administration in this study was due to FDC in lung TB patients given for only 5 months instead of the required 6 months, FDC administration in TB patients with type 2 diabetes that was not given for 9 months (TB infection could trigger increased variability in blood sugar), and patients with TB lymphadenitis who were not treated for 9 months.

For accurate delivery of FDC dosage, the dosage of FDC Category 1 was appropriate for $175(85.4 \%)$ subjects and that of FDC category 2 was appropriate for 4 subjects (1.9\%). Inappropriately administered doses were given to 26 patients (FDC Category 1 for 24 patients, 2 for 2 patients, and $0 \%$ FDC insertion). Inaccurate doses occurred due to improperly assigned FDC doses and injection of streptomycin for early weight treatment; the dosage of FDC and injection of streptomycin 


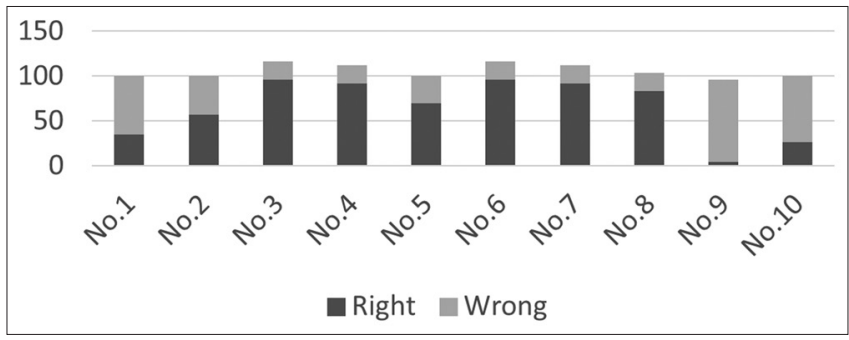

Fig. 1: The frequency distributions of correct answers and wrong answers to each question on the post-test questionnaire in the control group

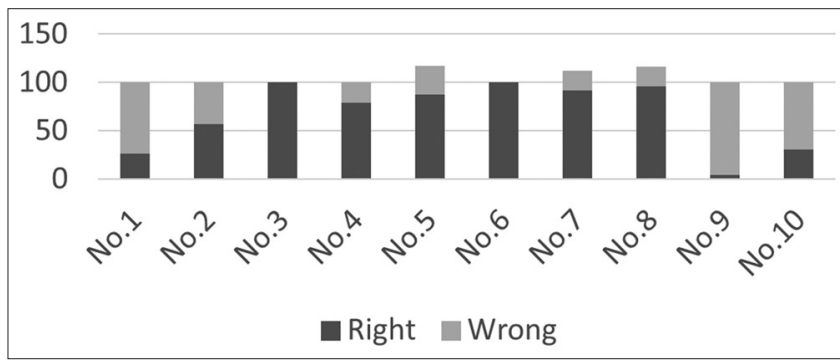

Fig. 2: The frequency distributions of correct answers and wrong answers to each question on the post-test questionnaire in the intervention group

did not follow by any weight gain. At this Community Health Center, streptomycin was given at a dose of $750 \mathrm{mg}$ for all patients' body weights, which is incorrect because if a patient has weight gain, the dose of FDC and streptomycin should also be adjusted $[7,8]$.

A study by Giri (2013) conducted at a health center in Surakarta with a total sample of 130 samples showed that the accuracy of FDC antiTB drug indication was $100 \%$, whereas the accuracy in our study was $96.6 \%$. This result was probably due to the larger sample used to increase the strength of the study. There were still 3.4\% inappropriate indications for anti-TB drug FDC because seven patients were AFB $(-)$, had no chest radiological examination, but received FDC anti-TB drug therapy. The accuracy of the given category, both in Giri's study (2013) and in this study, was $100 \%$. For the accuracy of dosing, Giri's study had a higher inaccuracy percentage $(17.7 \%)$ than in our study $(14.1 \%)$. In our study, the inaccuracy of the anti-TB drug FDC dosage was not caused by ignorance or neglect of the TB drug supervisor in the Community Health Center. The TB drug workers said that they were afraid of insufficient FDC anti-TB drug availability because each TB patient was given a box of FDC anti-TB drug. For the duration of FDC anti-TB drug in this study, there were still doubts among the TB officials about the duration of administration, especially in extrapulmonary TB patients and comorbid TB (e.g., type 2 diabetes mellitus); however, they rarely consulted with doctors to practice there because too many patients were treated at the Community Health Center, where medical personnel, places, and time are limited.

The inaccuracies in the duration of administration and the dose administered to the subjects of this study may lead to FDC anti-TB drug resistance, which means that patients will tend to fall into the MDRTB state in addition to the possibility of genetic polymorphism and transmission from other MDR-TB patients. It is important to avoid this because long-term treatment of MDR-TB and many unwanted effects of drugs can arise.

The patient side effects that were seen in this study were minor. In the event of major side effects, the patient was immediately referred to the nearest referral hospital. Research conducted by Samsu (2010) showed that among 168 study subjects, $23.2 \%$ experienced side effects [9]. In our study, side effects occurred only in $6.3 \%$ of patients and included heartburn (3.4\%), nausea (2.4\%), vomiting (1\%), joint pain $(1 \%)$, rash $(0.5 \%)$, and headache $0.5 \%$. Heartburn, nausea, and vomiting are usually caused by pyrazinamide anti-TB drugs, rifampicin, and isoniazid. Joint pain and headache are caused by rifampicin. Rash is caused by streptomycin, isoniazid, rifampicin, and pyrazinamide. However, because FDC is a combination of anti-TB drugs, it is difficult to determine with certainty the anti-TB drug that causes these side effects. There is no guidance on the management of these minor side effects at the Community Health Center, so management varies.

The results of this study showed that successful conversion increased from $71.2 \%$ to $81.1 \%$. Conversion failed due to inaccurate FDC dosage, inaccurate duration of FDC administration, or possibly due to pharmacogenetic effects. Further, research is needed in this area.

Among the 205 study subjects, 162 (79\%) had a drug supervisor and $43(21 \%)$ did not. However, because it cannot be seen in the secondary data, we could not assess the relationship between the drug supervisor and the TB patient. TB patients who do not have a drug supervisor tend to be self-assured. In addition, some TB patients live alone; therefore, a drug supervisor cannot be assigned.

In this study, 95.6\% (control group) and 95.6\% (interrupted drug supervisor group) of the TB patients had successful BTA sputum smears at 2 months of treatment, whereas $4.4 \%$ (control group) and $4.4 \%$ (intervention drug supervisor group) of the patients had unsuccessful conversion of BTA sputum. The cause of the failure of conversion is still unknown because the patient admitted taking regular medication and never missed it. Our policy is that if after FDC insertion for 1 month, the patient is still experiencing failure conversion; then, the patient will be given FDC Category II. At 6 months of treatment, data obtained from all TB patients showed a $100 \%$ success rate.

Analysis of the relationship between TB patients and their drug supervisors showed that the order of importance in the various relationships of the TB patients in the control group was brother/sister, husband/wife, other relatives, children, and then father/mother, whereas in the intervention group, the order of importance was father/mother, husband/wife, children, brother/sister, and other relatives. It is important to understand the relationship of TB patients with drug supervisors because if the drug supervisor is living with the TB patient, the task of directly monitoring the TB patient's compliance with taking regular medication becomes easier.

Among the 46 TB patients in the experimental study on the role of drug supervisors, $100 \%$ achieved compliance with pulmonary TB treatment for 6 months. Therefore, this study showed that there was no correlation between the knowledge level of the drug supervisor and patient compliance with pulmonary TB treatment for 6 months.

For research purposes 5-8, this study was only conducted in one District Community Health Center and three sub-district Community Health Centers in the North Jakarta area due to the limited time for this research. If extended to Community Health Centers throughout DKI with randomization, greater diversity among patients can be achieved to more accurately assess treatment suitability and compliance for 6 months.

\section{CONCLUSION}

Minor side effects of FDC anti-TB drugs did not affect the success of TB treatment; therefore, treatment was continued despite adverse events. There were no correlations between the knowledge level of the drug supervisor and medication compliance, sputum conversion (months 2 and 6), and treatment compliance with sputum conversion (months 2 and 6). At this Community Health Center, 100\% compliance with treatment for 6 months was achieved.

\section{CONFLICTS OF INTEREST}

All authors declare that they have no conflicts of interest. 


\section{REFERENCES}

1. Barreira D, Bloom A, Fujiwara P, Houben R, Kazatchkine, Kumar B, et al. Global Plan End to TB: The Paradigm Shift 2016-2020. Report Stop TB Partnership; 2015. p. 19-23.

2. Anderson L, Dean A, Falzon D, Floyd K, Baena I, Gilpin C, et al. Global Tuberculosis Report 2015. $20^{\text {th }}$ ed. Geneva: World Health Organization; 2015. p. 1-5.

3. Pletzer K, Louw J. Prevalence and factors associated with tuberculosis treatment outcome among hazardous or harmful alcohol users in public primary health care in South Africa. Afr Health Sci 2014;14:157-66.

4. World Health Organization. WHO Global Tuberculosis Report 2015. Global Tuberculosis Report 2015. 20 ${ }^{\text {th }}$ ed. Dalam: World Health Organization; 2015. p. 1-2

5. DKI Jakarta Public Health Office. Health Profile of DKI Jakarta
Province. Jakarta: DKI Jakarta Public Health Office; 2012. p. 26-276. Pademangan Community Empowerment Institute. Pademangan Health Center North Jakarta; 2010. p. 85-8.

6. Pademangan Community Empowerment Institute. Pademangan Health Center North Jakarta; 2010. p. 85-7.

7. Ministry of Health Republic of Indonesia. Current Situation Fact Sheet for Tuberculosis Control Progress. Vol. 2015; 2015. p. 1-5.

8. Isbaniyah F, Thabrani Z, Soepandi ZS, Burhan E, Reviono, Soedarsono, et al. Tuberculosis Diagnostic and Management Guidelines in Indonesia. Jakarta: Indonesian Respiratory Doctors Association; 2011. p. 1-66.

9. Rian S. Effect of Anti-Tuberculosis Drug Side Effects on the Occurrence of Defaults in Islamic Hospitals in Pondok Kopi Jakarta East January 2008-2010 [Thesis]. University of Indonesia Faculty of Public Health; 2010. p. 8-29. 